\title{
Physical Activity and Quality of Life of Obese Patients Before and After Bariatric Surgery
}

\section{Bruno Leandro de Melo Barreto*, Raphael José Perrier Melo, Jones Silva Lima, Rodrigo Conrado de Lorena Medeiros, Jani Cléria Pereira Bezerra}

Department of Surgery, University of Pernambuco, Brazil

*Corresponding Author: Bruno Leandro de Melo Barreto, Department of Surgery, University of Pernambuco, Brazil.

Received: April 22, 2019; Published: July 10, 2019

DOI: $10.31080 /$ ASGIS.2019.02.0056

\begin{abstract}
Unhealthy diet and physical inactivity are risk factors for the onset of obesity, considered an epidemic and public health issue facing society today. Bariatric surgery is one of the most effective treatments for obesity, reducing its complications. This work aimed to evaluate the physical activity level of obese patients before and after the surgery. The sample consisted of 12 obese patients submitted to bariatric surgery at Hospital das Clinicas, Universidade Federal de Pernambuco (HC-UFPE), where they were selected following the inclusion criteria and participated of two individual moments (before and after surgery), to answer both the Baecke questionnaire and the Short-Form Health Survey (SF-36). resultados (refazer em ingles).
\end{abstract}

Keywords: Bariatric Surgery; Physical Activity; Obesity and Quality of Life

\section{Introduction}

The obesity pandemic is considered a current public health problem throughout society, bariatric surgery is an efficient treatment for sustained weight loss and reduction of complications resulting from excess weight [1]. The main mechanisms involved are related to gastric restriction and intestinal malabsorption [2].

The loss of excess weight after bariatric surgery depends on changes in lifestyle, and the practice of physical activity is one of the most important factors. Preoperative slimming helps to reduce the risk of cycurigic and is proposed as a predictor of successful procedure. Regular physical activities improve emotional health and positively interfere with body image decomposition after surgery, and help maintain a healthy weight.

\section{Method}

This study is a descriptive comparative character of the observational type. The sample size consisted of 12 patients undergoing bariatric surgery (various techniques being the Bypass and Sleve the most used), between May and December 2014, attended at the Hospital das Clínicas of the Universidade Federal de Pernambuco (HC-UFPE). The subjects were selected from such criteria of inclusion: a) to be registered in the waiting queue system for bariatric surgery, b) to present body mass index (BMI) above 35 $\mathrm{kg} / \mathrm{m} 2$ (with comorbidities), and C) participate voluntarily in the research. However, those who: a) had a diagnosis of other diseases (for example: depression, hypertension, metabolic syndrome, diabetes), and b) those who did not participate in the second moment (post-surgical) were excluded.
After the selection criteria, the subjects included in the study participated individually in two moments (pre and post surgery) of completing the questionnaire of Baecke That evaluates the current level of physical activity of the practitioner, and the SF-36 (ShortForm Health Survey) that evaluates through eight subjective variables the quality of life of these patients, subdividing in functional capacity, limitation by physical aspects, pain, general health status, vitality, social aspects, emotional aspects and mental health.

The present study had a positive appreciation in the ethics Committee on Research with human beings of UFPE, under the CAAE-26594314.3.0000.5208, meeting the standards of resolution 466/12 of the National Health Council.

\section{Statistical analysis}

Descriptive statistical analysis of frequency was used for sociodemographic and clinical data, descriptive statistics of mean and standard deviation for the dimensions of quality of life obtained by the SF-36 and correlational statistics of the data between the two Moments (pre and post).

The use of descriptive statistics techniques aims to characterize the sample universe to be researched. Location and dispersion measurements were used to describe the collected data. Among the first, mean and median (Med.) were calculated, which are measures of central tendency. The dispersion measures estimate the variability existing in the data. For this purpose, it is estimated the standard error, the coefficient of variation (CV) and the standard deviation (s). It was also done a study of linear correlations be- 
tween the analytical variables, taken in their respective absolute values, as a way of complementing the statistical analysis of the intervariable relations.

Comparison of the mean values of the analytical variables of the temporal strata pre and post. Verification of association between the classifications by the cluster method in dichotomous mode, of the analytical variables in the respective delta values (Post/Pre). The study is of quasi Experimental characteristic (without control group) and in this perspective, we chose to work with the delta factor, which corresponds to the temporal variation observed intrasuway, from the ratio between the pre and post data, of each variable. In this construct, the values of the respective reasons are of an dimensionless and relative nature, and the Regardless of their order of magnitude, be compared to each other. In the case in question, we take the variations as analytical guiding.

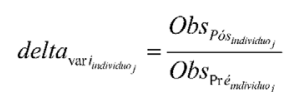

\section{Results}

The sample consisted of 12 subjects, three men and nine women, who were followed up in the pre-and post-surgery period. Table 1 shows the demographic data of the sample. It can be noted that the individuals $(n=12)$ were classified with obesity $(\mathrm{BMI}>$ $35 \mathrm{Kg} / \mathrm{m}^{2}$ ) grades III and IV.

\begin{tabular}{|l|c|c|}
\hline \multicolumn{1}{|c|}{ Variables } & Average & Standard deviation \\
\hline Age (years) & 37.6 & 10.6 \\
\hline Body Mass & 126.2 & 25.4 \\
\hline $\begin{array}{l}\text { Body Mass Index - BMI } \\
\left(\mathrm{kg} / \mathrm{m}^{2}\right)\end{array}$ & $45,9 \mathrm{Kg} / \mathrm{m} 2$ & 15,0 \\
\hline $\begin{array}{l}\text { Quality of life (SF-36) } \Sigma \\
\text { of indices }\end{array}$ & 3 & 0,7 \\
\hline $\begin{array}{l}\text { Total Physical Activity } \\
\text { level }\left(B \sum \text { of indexes }\right.\end{array}$ & 63,5 & 26,55 \\
\hline $\begin{array}{l}\text { Wait time for } \\
\text { revaluation }\end{array}$ & 16 weeks & - \\
\hline
\end{tabular}

Table 1: Demographic data of the pre-intervention sample $(\mathrm{N}=12)$.

Legend: $\sum$-summation.

According to the results obtained in the physical Activity level analysis questionnaires (SF-36 and Baecke), it is observed that at the moment pre-intervention all patients were with their levels of physical activity below normal. However, when applying the questionnaires after the surgical procedure (16 weeks), these values were modified, as shown in table 2 .

In relation to the results of the correlation performed between the instruments, according to table 3 (SF 36 and Baecker), it was observed that there was a significant correlation between the variables: emotional aspects with mental aspects $(r=$ value, $p=0.046)$.

\begin{tabular}{|c|c|c|c|c|c|c|}
\hline \multirow{2}{*}{$\begin{array}{l}\mathrm{N}=12 \\
\text { Baecke }\end{array}$} & \multirow{2}{*}{$\begin{array}{c}\begin{array}{c}\text { Analytical } \\
\text { Variable } \\
\text { Medium Delta }\end{array} \\
\text { Work index (IT) }\end{array}$} & \multicolumn{2}{|c|}{$\begin{array}{c}\text { Pre } \\
\text { Media D. P }\end{array}$} & \multicolumn{2}{|c|}{$\begin{array}{c}\text { Post } \\
\text { Media } \\
\text { D. P }\end{array}$} & \multirow{2}{*}{$\begin{array}{c}\begin{array}{c}\text { Test } t \\
\text { Cou- } \\
\text { plet }\end{array} \\
0.2043 \\
\end{array}$} \\
\hline & & 2.7 & 0.6 & 2.9 & 0.2 & \\
\hline & Sport index (IE) & 1.9 & 0.5 & 2.2 & 0.5 & 0.1366 \\
\hline & $\begin{array}{l}\text { Leisure Index } \\
\text { (IL) }\end{array}$ & 2.4 & 0.5 & 2.7 & 0.6 & 0.3588 \\
\hline & $\begin{array}{l}\text { Physical Activi- } \\
\text { ty Index (LAI) }\end{array}$ & 7.0 & 1.2 & 7.8 & 0.9 & 0.0999 \\
\hline \multirow[t]{8}{*}{ SF-36 } & $\begin{array}{c}\text { Functional } \\
\text { Capacity (CF) }\end{array}$ & 56.3 & 22.5 & 51.7 & 22.7 & 0.4875 \\
\hline & $\begin{array}{l}\text { Physical aspec- } \\
\text { ts (PA) }\end{array}$ & 52.1 & 48.2 & 33.3 & 43.1 & 0.1207 \\
\hline & Pain (Pain) & 62.8 & 26.3 & 68.2 & 20.5 & 0.4530 \\
\hline & $\begin{array}{l}\text { General health } \\
\text { status (EGS) }\end{array}$ & 58.9 & 11.2 & 57.0 & 10.7 & 0.4277 \\
\hline & Vitality (VT) & 56.7 & 18.5 & 49.2 & 11.6 & 0.1302 \\
\hline & $\begin{array}{l}\text { Social aspects } \\
\text { (AS) }\end{array}$ & 76.0 & 27.0 & 54.2 & 16.3 & 0.0024 \\
\hline & $\begin{array}{c}\text { Emotional } \\
\text { aspects (AE) }\end{array}$ & 63.9 & 46.0 & 49.9 & 43.8 & 0.2072 \\
\hline & $\begin{array}{c}\text { Mental Aspects } \\
(\mathrm{AM})\end{array}$ & 81.3 & 12.7 & 67.3 & 13.0 & 0.0001 \\
\hline
\end{tabular}

Table 2: Level of physical activity and quality of life of patients before and after surgical intervention.

Legend: $B$ IT: Work index IE: Sport index IL: Leisure index IAF: Physical activity index; SF-36 - CF: Functional Capacity AF: Physical aspects Pain: EGS Pain: General health status VT: Vitality AS:

Social aspects AE: Emotional aspects AM: mental aspects.

Once divided into groups, the elements analyzed for each analytical variable took such intravarable classifications and the test was applied not Parametric. To this end, it was observed a significance level $\mathrm{p}<0.05$ in the aspects related to the leisure index and emotional aspects that changed in this population after surgical intervention.

\section{Discussion}

In recent years, studies with obese patients have been concerned with verifying the relationship between the weight increment and the decrease of self-understanding in the health-related quality of life of these subjects. It can be noted that obese people report the presence of psychological sufferings resulting from interpersonal problems, often caused by prejudice and discrimination regarding the characteristics of eating behavior [3]. This is one of the main reasons for the need for follow-up in relation to self-perception of subjects regarding quality of life. Thus, the present study aimed to evaluate the level of physical activity and quality of life of obese subjects before and after bariatric surgery.

According to the results of the current investigation, it can be confirmed that the subjects achieved a higher level of physical ac- 


\begin{tabular}{|l|c|c|c|c|c|c|c|c|c|c|c|c|c|}
\hline & D_IT & D_IE & D_IL & D_IAF & D_BSQ & D_CF & D_AF & D_Dor & D_EGS & D_V & D_AS & D_AE & D_AM \\
\hline D_IT & 1.000 & & & & & & & & & & & & \\
\hline D_IE & -0.034 & 1.000 & & & & & & & & & & & \\
\hline D_IL & 0.255 & 0.164 & 1.000 & & & & & & & & & & \\
\hline D_IAF & 0.577 & 0.565 & 0.788 & 1.000 & & & & & & & & & \\
\hline D_BSQ & 0.700 & -0.128 & -0.137 & 0.187 & 1.000 & & & & & & & & \\
\hline D_CF & -0.318 & 0.201 & -0.075 & -0.106 & -0.507 & 1.000 & & & & & & & \\
\hline D_AF & 0.197 & 0.250 & -0.126 & 0.123 & 0.342 & 0.165 & 1.000 & & & & & & \\
\hline D_Dor & -0.017 & -0.150 & -0.196 & -0.202 & 0.013 & 0.510 & 0.134 & 1.000 & & & & & \\
\hline D_EGS & -0.318 & -0.043 & -0.130 & -0.265 & -0.621 & 0.364 & -0.309 & -0.319 & 1.000 & & & & \\
\hline D_V & 0.270 & 0.576 & 0.385 & 0.593 & -0.036 & 0.160 & 0.339 & -0.136 & 0.124 & 1.000 & & & \\
\hline D_AS & -0.286 & -0.035 & 0.128 & -0.097 & -0.553 & 0.539 & 0.150 & -0.013 & 0.729 & 0.319 & 1.000 & & \\
\hline D_AE & -0.228 & -0.038 & 0.270 & 0.054 & -0.459 & 0.296 & -0.714 & 0.069 & 0.414 & -0.129 & 0.292 & 1.000 & \\
\hline D_AM & -0.087 & 0.219 & 0.526 & 0.381 & -0.596 & 0.422 & -0.525 & -0.158 & 0.457 & 0.103 & 0.309 & 0.757 & 1.000 \\
\hline
\end{tabular}

Table 3: Linear correlations between analytical variables.

tivity after surgical intervention, compared to the beginning of the treatment of obesity. In this sense, the data obtained from the SF36 questionnaire indicate that the perception of the quality of life of the obese after the surgical procedure showed a slight improvement despite not being significant.

These results of the present study are in agreement with the findings in Vasconcelos' research [4], which identified improvements in the self-perception of obese patients undergoing the surgical procedure. Possibly the fact that there was no regular clinical intervention (psychological, physical exercise and nutritional orientation) during the postoperative period (16 weeks), the obese of the present study did not significantly modify their values regarding Quality of life obtained by the SF-36 questionnaire.

Another point to emphasize is that despite the Baecke Being an instrument often used in eutrophic subjects, it can be noted in the present study that the obese presented adequate results around the level of habitual physical activity after surgical intervention. Corroborating the findings of the study by Dumith., et al. [5], who identified a higher level of motivation in overweight adults when compared to eutrophic subjects (BMI $<25 \mathrm{~kg} / \mathrm{m} 2$ ). However, this result is not a parameter to determine the level of physical activity in the studied sample, because many times these patients present physical and social limitations due to excess weight [6].

Often only the surgical procedure is not sufficient to modify the behavioral pattern, much less the level of classification referring to the nutritional status of some patients. In some moments, many of these subjects have regained body mass7, due to factors that are closely related to this situation, such as inadequate feeding and not performing physical exercise.

One of the reasons reported on obesity nowadays is the result of busy life, lack of time to take care of food, moreover, the enormous commercial appeal of the food industry leads people to seek food faster, but not Nutritional [8]. A meta-analysis on physical activity and Bariatric surgery [9], cites that there was a significant increase in relation to the active time in the six months after the surgical procedure, with the addition of steps being the main observation with low intensity.

Studies have shown good results when the recommendation on physical activity is followed by the patient, with improvement in physical conditioning and cardiorespiratory conditioning [10], improvements also related to maintenance of muscle mass, lipotoxicity and improvements in $\beta$ cells, as well as insulin sensitivity [11]. Another study 12 Still cite that the Lifestyle modifications being diet, exercise and weight loss, continue to be the most effective therapy for non-alcoholic fatty liver disease.

These modifiable risk factors when not altered in the long term influence the decrease of the basal metabolic rate, consequently in the Increase in body fat components. Therefore, it is important to insert the practice of physical exercise in this population in pre-and post-bariatric surgeries, because simple exercise can minimize the risk of death, besides allowing improvements on the markers of physical fitness and health of this Population.

The main limitations of this study were the non-accomplishment of physical exercise after surgery and follow-up up to less than 12 months.

\section{Conclusion}

It is notorious that morbid obesity has a great relationship with low levels of physical activity, therefore they are intimately linked to the losses in the quality of life of the obese. Thus, it can be verified that bariatric surgery has been shown to be an efficient procedure for the control of obesity and an increase in the level of physi- 
cal activity. However, it is necessary to follow up these subjects continuously in the long term, for possible extrapolation of data regarding the magnitude of the benefits of the surgical procedure in this specific population and the possible changes in Life habits and level of physical activity.

\section{Summary}

Inadequate food and physical inactivity are risk factors for contributing to the onset of obesity. This, considered an epidemic, is a public health problem in society today. One of the most efficient treatments for obesity is bariatric surgery, because it reduces the complications of this. The objective of this work was to evaluate the level of physical activity of obese patients before and after surgery. The sample consisted of 12 patients attending the hospital of the clinics of the Federal University of Pernambuco (HC-UFPE), where they were selected from inclusion criteria and after this they participated in two individual moments (pre and post-surgery), to fill out the Baecke questionnaires and the SF-36 (Short-form health survey). Results: The aspects related to SF 36 with mean values of the analytical variables of the temporal strata pre and post: Applied the student $\mathrm{T}$ test, it was observed that there are significant differences (SIG. $\mathrm{p}<0.05$ ), between the mean values pre and post in Variables of the protocol SF36 \pm social aspects (sig. $\mathrm{P}=0.0024$ ), being pre $(76.0 \pm 27.0)>$ post $(54.3 \pm 16.2)$ and mental aspects (sig. $\mathrm{P}=0.0001)$, being pre $(81.3 \pm 12.7)>$ post $(67.3 \pm 13.0)$. For the other variables, no significant differences were observed. It is concluded that it is necessary to research with greater follow up to quantify the magnitude of the benefits of the surgical procedure in this specific population and the possible changes in life habits and level of physical activity.

\section{Acknowledgement}

Charles Albuquerque, Helena Cristina, Márcia and Mércia.

\section{Bibliography}

1. Sjostrom L., et al. "Effects of bariatric surgery on mortality in Swedish obese subjects". The New England Journal of Medicine 357 (2007): 741-752.

2. Cummings DE., et al. "Gatric by-pass for obesity: mechanisms of weight loss and diabetes resolution". The Journal of Clinical Endocrinology and Metabolism 89 (2004): 2608-2615.

3. Stunkard AJ and Wadden TA. "Psychological aspects of severe obesity". The American Journal of Clinical Nutrition 55.2-1 (1992): 524S-32S.

4. Vasconcelos PO. Quality of life in people undergoing bariatric surgery in pre-and post-surgical moments.

5. Dumith SC., et al. "Stages of change for physical activity in adults from Southern Brazil: a population-based survey". International Journal of Behavioral Nutrition and Physical Activity 4.25 (2007).
6. Fontaine KR., et al. "Health - related quality of life in obese persons seeking treatment”. Journal of Family Practice 43.3 (1996): 265-270.

7. Freire RH., et al. "Food quality, physical activity, and nutritional follow up as determinant of weight regain after Roux-en-Y gastricbypass". Nutrition 28 (2012): 53-58.

8. Mota MT. "Social discrimination suffered by obese people who are treated at the hospital of the acre clinics". In: Articles of the 7th exhibition of scientific production of the Lato Sensu postgraduation of PUC Goiás Sustainability, green economy and poverty eradication (2012).

9. Herring LY., et al. "Changes in physical activity behaviour and physical function after bariatric surgery: a systematic review and meta-analysis". Obesity Reviews (2016).

10. Huck CJ. "Effects of supervised resistance training on fitness and functional strength in patients succeeding bariatric surgery". The Journal of Strength and Conditioning Research 29 (2015): 589-595.

11. Coen PM and Goodpaster BH. "A role for exercise after bariatric surgery?". Diabetes, Obesity and Metabolism 18.1 (2016): 1623.

12. Hannah William $\mathrm{N}$ and Stephen A Harrison. "Effect of Weight Loss, Diet, Exercise, and Bariatric Surgery on Nonalcoholic Fatty Liver Disease". Clinics in liver disease 20.2 (2016): 339-350.

Volume 2 Issue 6 August 2019

(C) All rights are reserved by Bruno Leandro de Melo Barreto., et al. 